Portland State University

PDXScholar

$1-10-2021$

\title{
Connecting Policy to Licensed Assisted Living Communities, Introducing Health Services Regulatory Analysis.
}

Lindsey Smith

Portland State University

Paula Carder

Portland State University, carderp@pdx.edu

Taylor Bucy

Portland State University

Jaclyn Winfree

Portland State University

Joan F. Brazier

Brown University

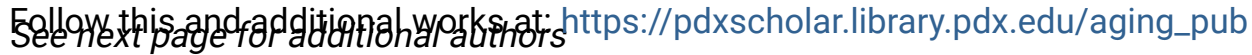

Part of the Gerontology Commons

Let us know how access to this document benefits you.

\section{Citation Details}

Smith, L., Carder, P., Bucy, T., Winfree, J., Brazier, J. F., Kaskie, B., \& Thomas, K. S. (2021). Connecting policy to licensed assisted living communities, introducing health services regulatory analysis. Health Services Research, 1475-6773.13616. https://doi.org/10.1111/1475-6773.13616

This Post-Print is brought to you for free and open access. It has been accepted for inclusion in Institute on Aging Publications by an authorized administrator of PDXScholar. Please contact us if we can make this document more accessible: pdxscholar@pdx.edu. 


\section{Authors}

Lindsey Smith, Paula Carder, Taylor Bucy, Jaclyn Winfree, Joan F. Brazier, Brian Kaskie, and Kali S. Thomas 


\title{
Connecting policy to licensed assisted living communities, introducing health services regulatory analysis
}

\author{
Lindsey Smith MPP ${ }^{1,2}$ (D) | Paula Carder PhD ${ }^{1,2}$ (D) | Taylor Bucy MPH ${ }^{3}$ (D) | \\ Jaclyn Winfree MS $^{2}$ | Joan F. Brazier MS ${ }^{4}$ Brian Kaskie PhD ${ }^{5}$ Kali S. Thomas PhD $^{4,6}$ (D)
}

${ }^{1}$ School of Public Health, Oregon Health \& Science University - Portland State University, Portland, Oregon, USA

${ }^{2}$ Institute on Aging, College of Urban and Public Affairs, Portland State University, Portland, Oregon, USA

${ }^{3}$ School of Public Health, University of Minnesota, Minneapolis, Minnesota, USA

${ }^{4}$ School of Public Health, Brown University, Providence, Rhode Island, USA

${ }^{5}$ College of Public Health, University of lowa, lowa City, lowa, USA

${ }^{6}$ Providence VA Medical Center, Providence, Rhode Island, USA

\section{Correspondence}

Lindsey Smith MPP, PSU Institute on Aging, P.O. Box 751, Portland, OR 97207-0751, USA.

Email: linsmith@pdx.edu

\section{Funding information}

National Institute on Aging, Grant/Award Number: R01AG057746; US Department of Veterans Affairs Health Services Research \& Development, Grant/Award Number: CDA 14-422

\begin{abstract}
Objective: To document dementia-relevant state assisted living regulations and their changes over time as they pertain to licensed care settings.

Data Sources: For all states, current directories of licensed assisted living communities and state regulations for each year, 2007-2018, were obtained from state agency websites and Nexis Uni, respectively.

Study Design: We identified multiple types of regulatory classifications for each state and documented the presence or absence of specific dementia care provisions in the regulations for each type by study year. Maps and summary statistics were used to compare results to previous research and document change longitudinally.

Data Collection/Extraction Methods: We used a policy analysis approach to connect communities listed in directories to applicable regulatory text. Then, we employed policy surveillance and question-based coding to record the presence or absence of specific policies for each classification and study year.

Principal Findings: Our team empirically documented provisions requiring dementiaspecific training for administrators and direct care staff, and cognitive impairment screening for each study year. We found that 23 states added one or more of these requirements for one or more license types, but the states that had these provisions for all types of licensed assisted living declined from four to two.

Conclusions: We identified significant, previously undocumented, within-state policy variation for assisted living licensed settings between 2007 and 2018. Using the regulatory classification instead of the state as the unit of analysis revealed that many policy adoptions were limited to dementia-designated settings. This suggests that people living with dementia in general assisted living are not afforded the same protections. We call our approach health services regulatory analysis and argue that it has the potential to identify gaps in existing policies, an important endeavor for health services research in assisted living and other care settings.
\end{abstract}

KEYWORDS

assisted living facilities, government regulation, health policy, health services, legal epidemiology, residential facilities 


\section{1 | INTRODUCTION}

Assisted living describes a wide variety of residential settings that provide long-term services and supports to older adults, including people living with dementia. These communities can offer social, recreational, personal, and health care services, as well as access to third party services such as hospice and home health. ${ }^{1}$ Increases in the assisted living market are correlated with declines in nursing home occupancy for private pay residents and residents with lowcare needs. ${ }^{2-4}$ Furthermore, there is a high prevalence of residents living in these settings with cognitive impairment and dementia, estimated at $70 \%$ and $40 \%$, respectively. ${ }^{5}$ These conditions impair residents' ability to advocate for themselves and increase information asymmetries between residents, their families, and care providers. ${ }^{6,7}$ As a result, it is essential for policy makers and researchers to understand how to best regulate this health service setting.

Regulatory overlap presents a significant barrier to conducting health policy studies, ${ }^{8,9}$ particularly in health service settings. ${ }^{10,11}$ Regulatory overlap results from two or more regulations intersecting through overlapping jurisdictions ${ }^{8}$ or context-specific policies. ${ }^{9}$ While the Federal government regulates hospitals, state and local agencies also have authority over various aspects of hospital operations. ${ }^{8}$ Multiple levels of government and multiple governing agencies are not the only source of this overlap. ${ }^{9}$ State agencies commonly use multiple levels of licensure and certification to regulate health service settings, responding to the different health needs within the population served. ${ }^{11}$ For example, hospitals, or units within hospitals, might serve patients with acute, traumatic, long-term, or mental health needs, or patients who are indigent. ${ }^{12,13}$ Studies have used legal epidemiology $y^{14}$ and health policy methodologies ${ }^{15,16}$ to document the influence of policies using the state as the unit of analysis. While these approaches are essential for analyzing policy impact and variation across states, regulatory overlap often results in variation within a state. ${ }^{8,17}$ The inherent vulnerability of people served in health service settings makes addressing this methodological gap especially important. ${ }^{7,18}$ We argue that regulatory overlap requires a more granular approach, linking policies with service settings.

Health policy analysis has traditionally compared policy adoption across states, such as an analysis of the impact of Medicaid expansion versus nonexpansion, or alternatively, has relied on secondary sources. ${ }^{19,20}$ In contrast, legal epidemiology provides methods to quantitatively measure law at a specific point in time. ${ }^{21-23}$ Policy surveillance, an approach within legal epidemiology, uses legal research methods to collect and map statutes to examine how policies differ across jurisdictions. ${ }^{21,24}$ Public health researchers have used policy surveillance output in comparative analyses, both those that track policy changes across jurisdictions and studies linking the policies to the health outcomes of their corresponding populations. ${ }^{14,25}$ For example, a recent study of state telehealth laws and opioid prescribing practices found that 17 states had laws to address prescribing limitations, opioid treatment, patient plan review, and professional collaboration, ${ }^{15}$ another study compared states' community health

\section{What This Study Adds}

- We identified significant and previously undocumented within-state variation in dementia-relevant assisted living policies adopted between 2007 and 2018.

- By integrating methods from legal epidemiology and health policy, our team found a growing divide in the regulatory protections offered to people living with dementia in assisted living communities with a dementiaspecific license or certification in comparison to those within the same state without one.

- We propose health services regulatory analysis as a novel approach to documenting the relationship between policies, such as administrative rules, and regulated health services in specified care settings, which ultimately allows for the identification of within-state variation.

worker laws, identifying differences in scope of practice and training requirements. ${ }^{16}$ While policy surveillance is an underutilized but potentially useful tool for health services researchers, ${ }^{23}$ it does not address the issue of overlapping regulations. ${ }^{26}$

Regulatory overlap of assisted living policies can occur through enforcement activities from multiple regulatory agencies or bodies, such as facility licensure by a health and human services agency, state Nurse Practice Acts that govern licensed nurses, and rules from local jurisdictions, such as county zoning regulations. ${ }^{27-29}$ Additionally, regulatory overlap can take place when state regulations vary to accommodate service variation. For instance, many states have additional policies for settings that provide dementia care. ${ }^{30,31}$ Assisted living communities are regulated at the state level, contributing to significant heterogeneity, in contrast with federal oversight of nursing facilities. ${ }^{29}$ The decentralized and variable regulatory environment of assisted living in the United States provides an apt setting for examining overlap.

A compendium of state assisted living regulations documented variation across, as well as within, states. ${ }^{29}$ For example, California has one primary type of assisted living, with an optional dementia care certification, ${ }^{32}$ while New York licenses three types of adult care facilities that offer different levels of supervision and personal care as well as a dementia care designation. ${ }^{33}$ How these and other state-level variations in licensing assisted living are organized and applied to specific communities has not been analyzed, to date. While our team had independently examined assisted living resident health service use ${ }^{34}$ and state assisted living requirements, ${ }^{29-31}$ we lacked a method to link state-level regulations to specific licensed care settings. In particular, despite the importance of dementia-specific training ${ }^{35,36}$ and cognitive impairment screening ${ }^{37}$ in assisted living, only state-level requirements have been documented, leaving us with a partial understanding of the variation in dementia care policies. 
This study had three objectives. The first was to identify requirements for dementia care, specifically staff training and cognitive screening for assisted living settings from 2007 to 2018. The second was to examine the regulatory overlap and resulting within-state variation in these rules. Finally, because existing analytic tools for documenting applicable regulations were inadequate to address regulatory overlap, we developed and validated an approach for systematically collecting and analyzing policies and their change over time, taking into account overlapping rules.

\section{2 | METHODS}

\section{1 | Study design}

The complexity of the assisted living regulatory environment and our intent to track detailed changes over time led us to develop an interdisciplinary approach by adapting policy surveillance ${ }^{38,39}$ and health policy analysis methodologies, ${ }^{20,40}$ integrating them within a health services research context. ${ }^{41}$ As reflected in Table 1, we used health policy's approach to sourcing policy texts, policy surveillance's approach to analyzing these texts, a novel approach to creating datasets from the texts, and a combined approach to analyzing the synthesized results. We used the policy analysis approach of analyzing the regulations, ${ }^{40}$ which veers from policy surveillance's use of statutory law. ${ }^{39}$ We analyzed these legal texts using dichotomous analytic questions, following the policy surveillance process, which accounts for regulatory overlap by defining assisted living regulatory classification as the unit of analysis. We summarized these analyses using maps and descriptive statistics.

\section{2 | Data source}

Our study relied upon two forms of data: administrative records and state regulatory text. The first dataset came from a national census of licensed assisted living settings collected by our team for the years 2017 and 2019, following a method documented in prior work. ${ }^{34}$ This dataset included license type, residence name, address, and capacity information. The second dataset consisted of state assisted living regulations effective as of the end of each year for years 2007 through 2018, sourced using Nexis Uni from the LexisNexis legal database.

\section{3 | Data collection}

We reviewed the dataset of assisted living directories for license types, certifications, or designations in use within each state for all study years. Using Nexis Uni, we sourced the 138 administrative code chapters containing 5,011 regulations licensing and certifying assisted living and assisted living administrators, as well as an archived copy of these regulations for each study year. Statutes were used for one state (Minnesota) and one of the license types in District of Columbia, both of which lacked licensing regulations during the study period.

\subsection{Defining the unit of analysis}

Using policy analysis methods informed by our previous work, ${ }^{29,31}$ we identified three types of regulatory classifications used by state agencies: (a) primary license, a stand-alone license type that is mandatory for all providers of a particular type; (b) sublicense,

TAB LE 1 Health services regulatory analysis process as applied to assisted living

\begin{tabular}{|c|c|c|c|c|}
\hline $\begin{array}{l}\text { Development and } \\
\text { scope }\end{array}$ & Collection of regulations & Question coding & $\begin{array}{l}\text { Review and } \\
\text { verification }\end{array}$ & $\begin{array}{l}\text { Nominal data } \\
\text { output }\end{array}$ \\
\hline $\begin{array}{l}\text { Built lists of } \\
\text { licensed assisted } \\
\text { living facilities } \\
\text { using state } \\
\text { directories; } \\
\text { defined } \\
\text { conceptual scope }\end{array}$ & $\begin{array}{l}\text { Identified and downloaded } \\
\text { assisted living licensing } \\
\text { regulations from Nexis } \\
\text { Uni }\end{array}$ & $\begin{array}{l}\text { Used question-based coding to record } \\
\text { variation in regulations across analytic } \\
\text { classifications of assisted living licensing } \\
\text { and certification }\end{array}$ & $\begin{array}{l}\text { Engaged in inter-rater } \\
\text { reliability practices } \\
\text { and team review } \\
\text { of work to ensure } \\
\text { reliability }\end{array}$ & $\begin{array}{l}\text { Combined coded } \\
\text { datasets for each } \\
\text { classification to } \\
\text { create nominal } \\
\text { variables } \\
\text { associated with } \\
\text { each question } \\
\text { and license } \\
\text { type, including } \\
\text { those combining } \\
\text { multiple } \\
\text { classifications }\end{array}$ \\
\hline
\end{tabular}

Note: The health services regulatory analysis approach is based on the policy surveillance process, but adapted to the needs of health services researchers. By using administrative licensing and certification to define the unit of analysis, in place of states, an analysis of regulated health service settings is possible.

Source: Authors' documentation of data collection and analytic process. 
representing one of multiple categories that providers must choose from when seeking licensure; and (c) designations, a classification type we used to record modifiers applicable to primary or sublicense types. Designations include optional certifications and disclosures that providers can report or otherwise qualify for in addition to their primary license or sublicense. ${ }^{11}$ In some states, these designations grant providers allowances to provide or advertise particular services (eg, nursing care), or to admit and retain a specified subpopulation (eg, people living with dementia). ${ }^{30}$

This multifaceted approach to categorizing regulated settings is necessary due to the varying approaches used by states. For example, Arkansas has two primary licenses of assisted living: Assisted Living Facilities and Residential Care Facilities. ${ }^{42-44}$ Assisted Living Facility licenses include two sublicenses, Level I or Level II, indicating the provider's ability to care for residents of lower (LI) or higher (LII) medical acuity. Either level can pursue an Alzheimer's Special Care Unit certificate, resulting in two additional possible types of combined sublicense-designation. ${ }^{42,43}$ Combined, these classifications result in five distinct types of licensed assisted living with different applicable rules, resulting in different allowed services and, theoretically, different resident makeup.

\section{5 | Question coding}

After sourcing the relevant regulations for primary, sub-, and designation classifications for each state and year, we developed questions for coding the regulatory texts. This approach, used in both policy surveillance and qualitative research, ${ }^{45,46}$ models qualitative coding, except that answers to questions rather than codes (ie, question coding) were applied to the regulatory text. ${ }^{47}$ While there are many policies important to dementia care, we chose to investigate dementia-specific training and cognitive screening due to the existing research showing the impact of these policies. ${ }^{35-37}$ To understand dementia care requirements, the team developed questions about dementia care staffing and cognitive screening and then answered those questions using each state's regulatory text for each study year and classification; see Figures 1-3 for full question text. We answered the questions for each classification separately to allow us to identify which types of licensed settings for each state had relevant applicable provisions. The resulting dataset consisted of dichotomous variables ( $1=$ yes; $0=$ no) and their accompanying policy reference (eg, chapter).

We assigned a "silent" variable (coded as 9) when the regulatory text lacked evidence clearly indicating a "yes" or "no" response. For instance, if a state's assisted living regulations lacked text describing cognitive screening, we assigned a "9" code because ancillary regulations outside of our scope might be relevant. For settings with overlapping regulatory requirements, the answers recorded for each classification applicable were combined using the R statistical environment. ${ }^{48}$ Designation answers were used to modify primary or sublicense answers, and when multiple licenses were applicable, both the most and least restrictive responses were recorded for use based on specific future analytic needs. By first breaking all question coding into data entry sheets specific to each classification, then combining these sheets during the data processing stage,
A. Requirements by State, 2007

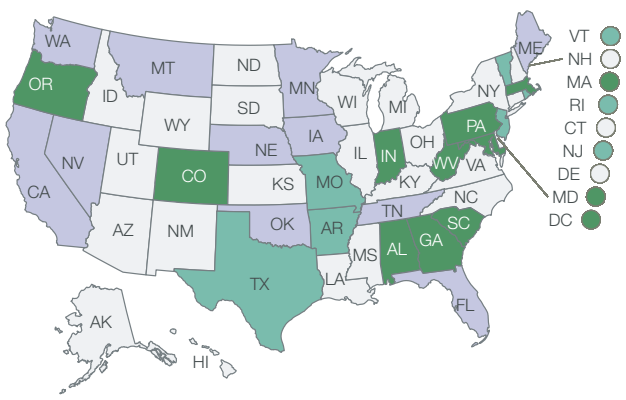

Legend

Yes - All License Types

Yes - Some License or Sub-License Types

Yes - Dementia-Designated Only

No Regulation Within Scope
B. Requirements by State, 2018

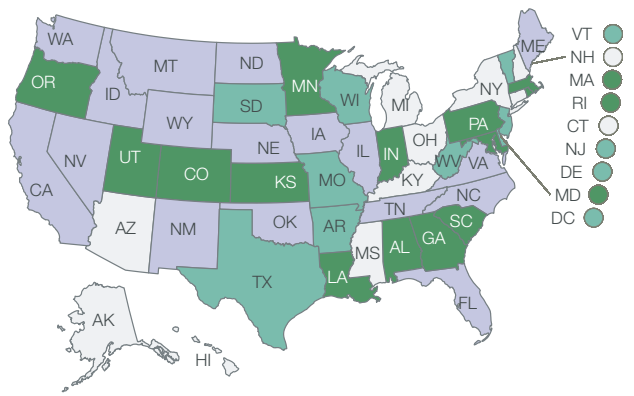

C. Previous Research Findings (Burke et al., 2015)

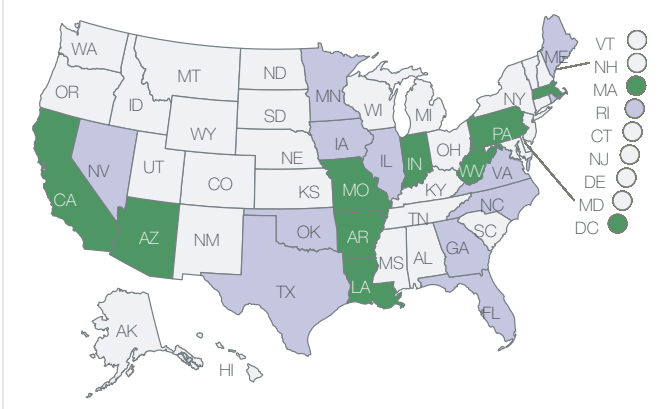

FIGURE 1 Is Dementia-Specific Initial Training Required for Assisted Living Direct Care Workers? 
A. Requirements by State, 2007

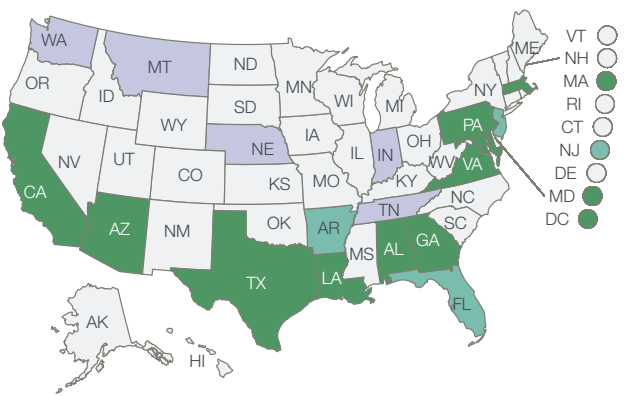

Legend

Yes - All License Types

Yes - Some License or Sub-License Types

Yes - Dementia-Designated Only

No Regulation Within Scope
B. Requirements by State, 2018

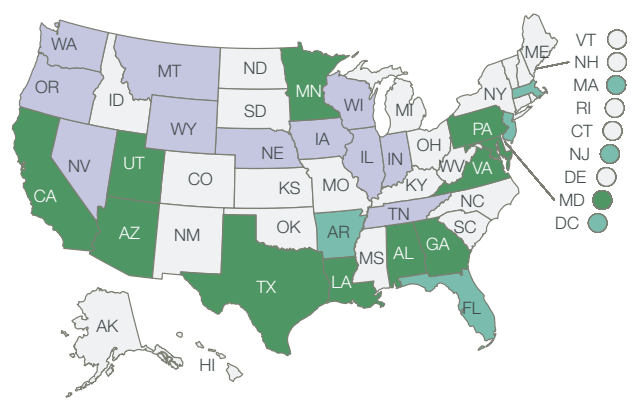

C. Previous Research Findings (Carder, 2017)

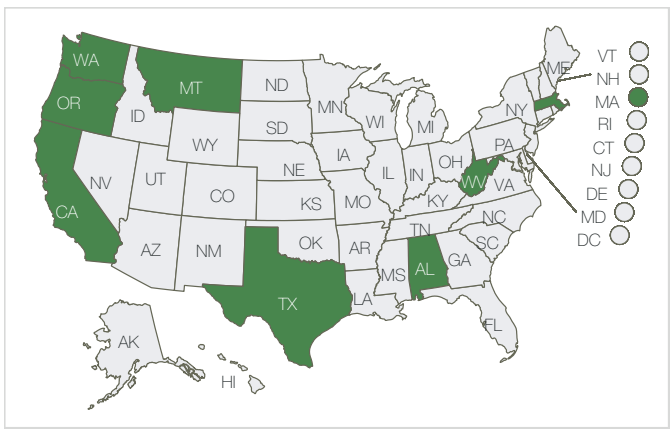

FIGURE 2 Is Dementia-Specific Initial Training Required for Assisted Living Administrators?

A. Requirements by State, 2007

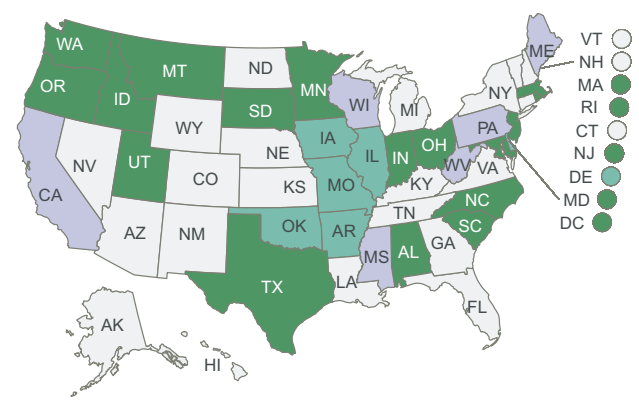

Legend

Yes - All License Types

Yes - Some License or Sub-License Types

Yes - Dementia-Designated Only

No Regulation Within Scope
B. Requirements by State, 2018

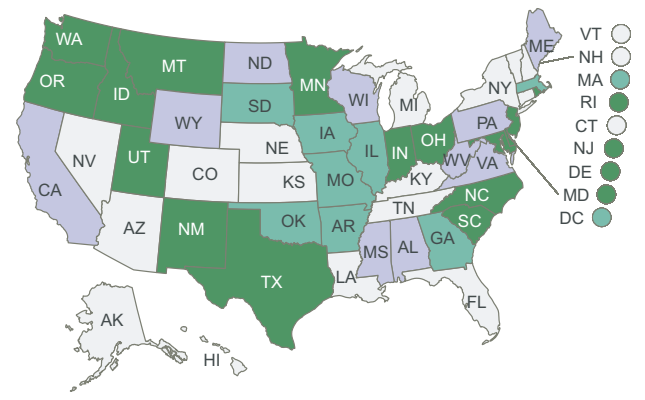

C. Previous Research Findings (Carder, 2017)

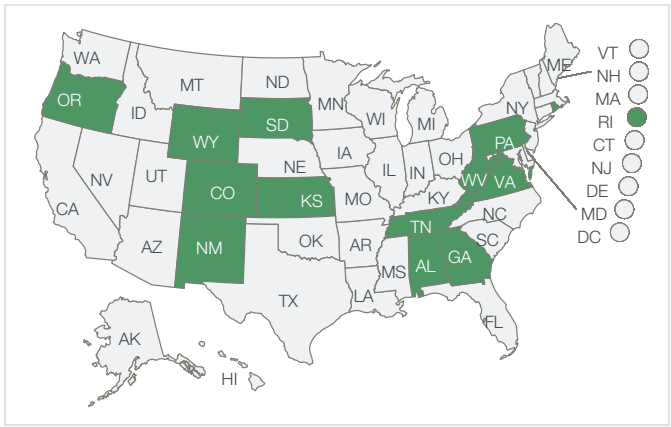

FIGURE 3 Is Screening Residents for Cognitive Impairment Required at Admission? 
we quantified the content of assisted living regulations, even in instances of regulatory overlap.

\subsection{Coder training and inter-rater review}

To ensure consistency in the coding approach, all team members, including a co-investigator, a health policy doctoral student, masterstrained research analyst, four master's students with experience in qualitative research or policy, received training. Specific training steps included keyword development used for searching regulatory text (eg, dementia, Alzheimer, cognitive impairment), weekly discussions of question coding, coding in two-person teams, and consensus on decision criteria. Once team members began coding independently, each was assigned another team member's data entry forms to review, and the full team met to resolve any differences. This iterative process continued until team member coding methods were aligned, a standard method in both qualitative research ${ }^{47}$ and legal epidemiology methods. ${ }^{45}$ All team decisions were documented, providing an audit trail. ${ }^{49}$

\section{3 | RESULTS}

We identified 182 license classifications, representing 45 primary license types, 71 subtypes, and 66 designations that are combined by regulators in a total of 350 different ways. Our use of state directories allowed us to identify 99 regulatory classifications not previously documented in summaries of assisted living regulations. ${ }^{29,50}$ Provisions for licensing levels of care theoretically correspond to policy makers and rulemakers' perceived levels of need for protection. Additional certifications or disclosures designated as applicable to a community reflect specific protections for subpopulations based on vulnerabilities related to health status or diagnosis (eg, dementia, mental illness, traumatic brain injury) or to economic status (eg, Medicaid).
By breaking out findings by license types, for dementia-specific training, we found that 28 states $(55 \%)$ required initial training for direct care workers in 2007. Of these, 11 states required dementia training for all licensed settings; six states required this training in some, but not all license types; and 11 states specified the training was only necessary for dementia-designated care settings. As shown in Figure 1, by 2018 , 41 states (80\%) had either requirements for all settings (14), some licensed settings (10), or only dementia-designated settings (17). In comparison, a 2015 legal review of dementia-specific initial training for direct care workers identified 21 states (41\%) with these requirements, in either all settings (6) or only for dementia "special care" units (15). ${ }^{51}$ As documented in Table 2, we found that 17 states added or changed the scope of this provision. However, in 2018 there were still only 14 states that required this type of training for all licensed assisted living settings.

In 2007, 19 states (37\%) required dementia-specific training for administrators in all licensed assisted living settings (11), some licensed settings (3), or only dementia-designated settings (5). As shown in Figure 2, while 10 states made changes resulting in 27 states with requirements in 2018 , the number of states in which all licensed settings had this requirement was still 11 in 2018, indicating that most states added these requirements for a subset of assisted living communities. In comparison, Carder's ${ }^{30}$ analysis of a secondary source of regulations reported that eight states (16\%) required dementia-specific training for administrators. ${ }^{30}$

In our review of cognitive screening requirements, shown in Figure 3, we found 10 states that either introduced or changed the scope of cognitive screening requirements between 2007 and 2018 resulting in a decrease in the number of states requiring a cognitive screen at admission for all types of licensed settings. In 2007, 30 states (59\%) had requirements for all license types (18), some license types (6), or only dementia-designated settings (6). This increased to 35 states $(69 \%)$ in 2018 , of which only 16 had requirements for all licensed settings. In contrast, Carder's review (2017) found 13 states (25\%) with these requirements. ${ }^{30}$

TABLE 2 Changes to dementia-specific regulations over time

\begin{tabular}{|c|c|c|c|c|c|c|c|c|c|}
\hline \multirow[b]{3}{*}{$\begin{array}{l}\text { Dementia-specific training and } \\
\text { screening requirements }\end{array}$} & \multicolumn{4}{|c|}{ States with requirements 2007} & \multicolumn{5}{|c|}{ States with requirements 2018} \\
\hline & \multirow[b]{2}{*}{$\begin{array}{l}\text { None } \\
\text { found }\end{array}$} & \multicolumn{3}{|c|}{ Rule identified } & \multirow[b]{2}{*}{$\begin{array}{l}\text { None } \\
\text { found }\end{array}$} & \multicolumn{3}{|c|}{ Rule identified } & \multirow[b]{2}{*}{$\begin{array}{l}\text { Any change } \\
\text { '07-'18 }\end{array}$} \\
\hline & & $\begin{array}{l}\text { Dementia } \\
\text { only }\end{array}$ & $\begin{array}{l}\text { Some } \\
\text { license } \\
\text { types }\end{array}$ & $\begin{array}{l}\text { All license } \\
\text { types }\end{array}$ & & $\begin{array}{l}\text { Dementia } \\
\text { only }\end{array}$ & $\begin{array}{l}\text { Some } \\
\text { license } \\
\text { types }\end{array}$ & $\begin{array}{l}\text { All license } \\
\text { types }\end{array}$ & \\
\hline Direct care worker initial training & 23 & 11 & 6 & 11 & 10 & 17 & 10 & 14 & 17 \\
\hline Administrator initial training & 32 & 5 & 3 & 11 & 24 & 11 & 5 & 11 & 10 \\
\hline Cognitive screening at admission & 21 & 6 & 6 & 18 & 16 & 10 & 9 & 16 & 10 \\
\hline One or more requirements & 39 & 16 & 11 & 26 & 30 & 24 & 16 & 26 & 23 \\
\hline All requirements & 11 & 0 & 1 & 4 & 7 & 1 & 2 & 3 & 2 \\
\hline
\end{tabular}

Note: Regulatory analysts relied upon state regulations to record whether each potential requirement was present, absent, or specified as not required. Direct care workers refer to assisted living employees providing assistance to residents on a daily basis. One or more requirements refers to the number of states that require one or more of the three potential requirements listed; all requirements refers to the number of states that enforce all three of these rules for all, some, or only dementia-designated licensed assisted living communities.

Source: Authors' analysis of state assisted living regulations for years 2007 and 2018. 
In all, there were 23 states that made changes to at least one of these three potential rules between 2007 and 2018. Table 2 additionally shows that looking across these recommended regulations, in 2007, four states-Alabama, District of Columbia, Massachusetts, and Maryland-had instituted these policies for all licensed settings. By 2018, three of those states had dropped the provision or added a license that lacked the requirement and only one state added these provisions for all license types, resulting in two states with all three provisions for all licensed settings.

\section{4 | DISCUSSION}

This study empirically recorded within-state variation by using state regulatory classifications to link regulations to specific assisted living communities. This allowed us to identify regulatory variation within and across states, in comparison with the limited state-level approaches previously reported. This work advances our understanding of the relationship between the protections these regulations offer assisted living residents and the corresponding variation in services allowed in these settings. These findings suggest reframing the current conception of both how to describe assisted living regulation and how these regulations have changed over time. We call our approach health services regulatory analysis, referring to the process of combining policy analysis and legal epidemiology methods while using licensure and certification as the unit of analysis. We increased the accuracy of our findings in comparison with previous policy mapping research, while additionally uncovering significant within-state regulatory variance. These findings have broad implications for future research in assisted living, as well as for others looking to examine the relationship between overlapping policies and the specific care settings to which they apply.

\section{1 | Previous research}

In comparing our findings to previous research, some of the differences we found are due to the strength of policy surveillance methods in empirically documenting legal data. While health services researchers have traditionally relied upon policy analysis, policy surveillance provides a rigorous process for documenting policy variation over time, and ensuring comparable results across jurisdictions in scope. ${ }^{22,38}$ Burris et al ${ }^{39}$ recommend reviewing the relevant provision in the context of the full legal text, ensuring coding decisions are based on the contextual meaning and definitions specified. For example, our approach found that only supervisors of direct care workers in Arizona must complete dementia-specific initial training, while Burke et al $^{51}$ reported that direct care staff must also do so. Thus, our approach can limit mischaracterizations of the policy in comparison with other states.

Our use of regulatory classifications as the unit of analysis produced additional differences compared with others' research. For example, in Texas, assisted living can be licensed as either type A or type $\mathrm{B}$, with type $\mathrm{B}$ allowing for an additional dementia care certification. ${ }^{52}$ While Burke et al $^{51}$ identified the requirement for dementia-specific training for direct care staff only in assisted living certified for dementia care, this requirement actually applies to all type B facilities, even those without the certification. Thus, understanding within-state variation permits a more granular analysis of assisted living regulations.

Policy advocates and researchers studying assisted living have commonly held that dementia care policies have been adopted by a growing number of states. We found that while this is true for dementia-designated settings, it may not be for general assisted living. By capturing within-state variation, we identify regulatory change over time that would otherwise be masked by a consistent statelevel response. Tracking responses to questions over the course of 12 years at the license level allowed us to identify states that changed their regulatory approach, while also identifying which populations the changes impacted.

\section{2 | Limitations}

This study was limited by the analytic scope, which included only regulations for license types that could accommodate 25 or more residents. Regulatory variation between and within states may differ in important ways for smaller settings. In addition, if states use auxiliary policies to regulate assisted living, such as Nurse Practice Acts or Public Health Laws that specify requirements not found in the assisted living regulations, our current findings would indicate the state was "silent" for that license type. These and other auxiliary policies could be analyzed in future research using the approach described in this paper.

\section{3 | Implications for assisted living}

To date, researchers have largely used the state as the unit of analysis when examining assisted living regulations. Our findings regarding changes to dementia care rules over time add previously undocumented nuance to understanding how assisted living regulation changed between 2007 and 2018. We identified 20 states that added dementia care rules, strengthening the regulatory oversight, consistent with previous findings. However, by recording these changes by regulatory classification, we found that these three dementia care provisions have not been consistently strengthened by state policy and rulemakers. While these rules have become more broadly applied to dementia-designated care settings, as of 2018 , only two states required that all types of licensed assisted living settings train administrators and direct care staff in dementia care and screen admitted residents for cognitive impairment. This finding is particularly concerning given the known prevalence of people living with dementia in all assisted living communities and that counties with dementia-designated assisted living are more educated, wealthy, and have fewer Black residents in comparison to those with 
one or more assisted living communities without a dementia care designation. ${ }^{53}$

Our findings suggest that prior research on assisted living regulations has not comprehensively characterized the within-state variation in the application of key policies. As a result, states' sublicenses and designations intended to protect subgroups of assisted living settings and residents (eg, people living with dementia) have not been represented and have been documented as rules that are enforced in all settings. For example, if dementia-specific staff training is only required in dementia-designated settings, people living with dementia in assisted living settings without this designation may receive care from staff that lack relevant skills. Although such a state would have been previously documented as providing dementia-specific staff training, this accounting misses the true scope of the regulation.

The between-state variation we identified is consistent with previous studies of assisted living regulations. ${ }^{30,31,54}$ Some of these studies argue that this variation, in and of itself, warrants the need for federal oversight. ${ }^{31,54}$ While we identified between-state variation, our approach identified that within-state variation plays a large role, as represented by the case of dementia-specific staff training. Researchers that use the state as the unit of analysis would report that $80 \%$ of states have dementia-specific initial training requirements for direct care workers, thereby ignoring that these rules apply only to a subset of assisted living communities. In contrast, we found that as of 2018 , only 14 states $(27 \%)$ required such training in all settings. Thus, it is possible that far fewer assisted living settings than previously thought are required to meet these training standards due to within-state variation, indicating a need for additional research to document the true relationship between regulations, regulatory structures, and resident health outcomes.

By integrating methods from policy surveillance and health policy analysis within a health services context, we extend the application of these methods to better understand the relationship between state regulations and population health. The extent to which the identified between- and within-state variation in regulation affects providers' behaviors and residents' outcomes is unknown, but can be assessed using the dataset described here. The dataset can now be linked with Medicare claims using the methodology developed by our team to identify Medicare beneficiaries residing in licensed assisted living settings ${ }^{34}$ to assess how specific policies and changes in state requirements impact residents' health-related outcomes.

\subsection{Implications for health services research}

Although health policy analysis and policy surveillance methodologies can be used to study the connection between policy and health outcomes, ${ }^{23,24,55}$ neither approach offers a process for analyzing multiple overlapping policies applicable to specific settings. ${ }^{26}$ Investigating the role of policy in health service settings is challenging when compared to population-wide public health laws, particularly due to the added complexities introduced by regulatory overlap. Policy surveillance is an underutilized tool for empirically mapping policy, and health policy analysis has proven an invaluable tool for assessing policy impact. However, when used in isolation, these existing methods do not address the challenges inherent in health service settings such as regulatory overlap.

Variation in the applicable rules within each state have often been overlooked, or considered to be an unnecessary bureaucratic burden. ${ }^{56}$ However, this variation allows agency staff to accommodate the many areas of expertise needed for monitoring and allows providers flexibility as they adapt to population-specific needs. ${ }^{56,57}$ For example, studies investigating the licensing and certification approaches of substance abuse treatment programs and neonatal units found that variation within these regulatory structures impacted service outcomes. ${ }^{58-60}$

Our health services research analysis approach provides a process for collecting and analyzing policy of relevance to health services research aims because it allows researchers to identify and assess the effects of different policies both within and across states. Our team used health services regulatory analysis to document one type of regulatory overlap-that resulting from multiple license types, tiers, and simultaneously applicable certifications and designation structures. We argue that this approach could be similarly used in other types of regulatory overlap, such as overlapping regulations from various levels of government or the involvement of multiple agencies.

Collecting all applicable rules for health service settings and combining them for analysis would allow for a nuanced assessment of regulations that govern services delivered to specific population groups. For example, nursing facilities and hospitals are both subject to jurisdictional overlap due to the presence of state and federal oversight. While nursing homes are largely governed at the federal level, federal regulations intersect with state-level certificate-of-need and public health rules, mediating the impact of federal requirements on facilities and residents. ${ }^{61}$ Other examples include hospice agencies, group homes that serve various populations, and adult day health programs. A future study looking to identify local- and state-level variation in adult day health programs' registered nurse staffing could use our approach to examine the presence of within-state regulatory variation, and the impact, if any, of how the federal requirements are applied to different service users. ${ }^{62}$

In sum, an approach to examine regulatory overlap is particularly needed to document differential access to, and use of, health service settings that both result from and contribute to health disparities. ${ }^{63}$ Documenting regulatory protections for different population groups requires an approach that allows for regulatory overlap and a more granular policy documentation than current state-based approaches permit. Future research using this approach can examine, for example, whether and how subpopulations, such as residents who are Medicaid beneficiaries, racially or ethnically diverse, or who have specific medical diagnoses, experience disparities in access or outcomes associated with regulatory classifications within existing regulated health services. 


\section{ACKNOWLEDGMENTS}

Joint Acknowledgment/Disclosure Statement: The work presented in this paper was supported by the National Institute on Aging (R01AG057746 to KST) Do State Regulations Affect the Outcomes of Assisted Living Residents with Dementia? and the US Department of Veterans Affairs Health Services Research \& Development (CDA 14-422 to KST).

The views expressed in this article are those of the authors and do not necessarily reflect the position or policy of the National Institutes of Health, Department of Veterans Affairs, or the United States government.

We thank Laken Harrel and Christina Nguyen from the Oregon Health \& Science University - Portland State University School of Public Health, Kaylin Dugle, May Swihart, and Margaret Mitzel of Portland State University, and Seamus Taylor and Delaney Bounds from the University of lowa for their help sourcing and coding regulatory documents. Wenhan Zhang and Dr. Portia Cornell of Brown University provided guidance in defining the regulated setting types. We acknowledge Andrew Campbell of Temple University for providing policy surveillance training to our team. The authors have no other disclosures.

\section{ORCID}

Lindsey Smith iD https://orcid.org/0000-0003-4630-3114

Paula Carder http://orcid.org/0000-0002-8584-5226

Taylor Bucy iD https://orcid.org/0000-0002-9049-1100

Kali S. Thomas (iD https://orcid.org/0000-0003-3436-2184

\section{REFERENCES}

1. Chapin R, Dobbs-Kepper D. Aging in place in assisted living: philosophy versus policy. Gerontologist. 2001;41(1):43-50. https://doi. org/10.1093/geront/41.1.43

2. Grabowski DC, Stevenson DG, Cornell PY.Assisted living expansion and the market for nursing home care. Health Serv Res. 2012;47(6):22962315. https://doi.org/10.1111/j.1475-6773.2012.01425.x

3. Cornell PY, Zhang W, Thomas KS. Changes in long-term care markets: assisted living supply and the prevalence of low-care residents in nursing homes. J Am Med Dir Assoc. 2020;21(8):1161-1165.e4. https://doi.org/10.1016/j.jamda.2020.01.006

4. Silver BC, Grabowski DC, Gozalo PL, Dosa D, Thomas KS. Increasing prevalence of assisted living as a substitute for private-pay longterm nursing care. Health Serv Res. 2018;53(6):4906-4920. https:// doi.org/10.1111/1475-6773.13021

5. Zimmerman S, Sloane PD, Reed D. Dementia prevalence and care in assisted living. Health Aff (Millwood). 2014;33(4):658-666. https:// doi.org/10.1377/hlthaff.2013.1255

6. Carr A, Biggs $\mathrm{S}$. The distribution of regulation in aged and dementia care: a continuum approach. J Aging Soc Policy. 2020;32(3):220-241. https://doi.org/10.1080/08959420.2018.1528113

7. Rosenbaum MS, Seger-Guttmann T, Giraldo M. Commentary: vulnerable consumers in service settings. J Serv Mark. 2017;31(4/5):309312. https://doi.org/10.1108/JSM-05-2017-0156

8. Freeman J, Rossi J. Agency coordination in shared regulatory space. SSRN Electron J. http://dx.doi.org/10.2139/ssrn.1778363

9. Turk MC. Overlapping legal rules in financial regulation and the administrative state. SSRN Electron J. http://dx.doi.org/10.2139/ ssrn. 3250215
10. Abelkop ADK. Tort law as an environmental policy instrument. Or $L$ Rev. 2013;92(381):410-422. https://ssrn.com/abstract=2297105

11. Rooney AL, Van Ostenberg PR. Licensure, Accreditation, and Certification: Approaches to Health Services Quality. Quality Assurance Methodology Refinement Series. Bethesda, MD: Center for Human Services; 1999.

12. Polsky D, David G, Yang J, Kinosian B, Werner R. The effect of entry regulation in the health care sector: the case of home health. J Public Econ. 2014;110:1-14. https://doi.org/10.1016/j.jpubeco.2013.11.003

13. BlumJ.Arevisionistmodel ofhospital licensure. Regul Gov.2008;2(1):4864. https://doi.org/10.1111/j.1748-5991.2007.00027.x

14. Martini L, Presley D, Klieger S, Burris S. A scan of CDC-authored articles on legal epidemiology, 2011-2015. Public Health Rep. 2016;131(6):809-815. https://doi.org/10.1177/0033354916669497

15. Pepin D, Hulkower R, McCord R. How are telehealth laws intersecting with laws addressing the opioid overdose epidemic? J Public Health Manag Pract. 2020;26(3):227-231. https://doi.org/10.1097/ PHH.0000000000001036

16. Fulmer EB, Barbero C, Gilchrist S, et al. Translating workforce development policy interventions for community health workers: application of a policy research continuum. J Public Health Manag Pract. 2020;26:S10. https://doi.org/10.1097/PHH.0000000000 001123

17. Goodman CB. Jurisdictional overlap and the size of the local public workforce. State Local Gov Rev. 2018;50(1):15-23. https://doi. org/10.1177/0160323X18774402

18. Hurst SA. Vulnerability in research and health care; describing the elephant in the room? Bioethics. 2008;22(4):191-202. https://doi. org/10.1111/j.1467-8519.2008.00631.x

19. Walt G, Shiffman J, Schneider H, Murray SF, Brugha R, Gilson L. 'Doing' health policy analysis: methodological and conceptual reflections and challenges. Health Policy Plan. 2008;23(5):308-317.

20. An R, Huang C, Baghbanian A. Health policy analysis. In: Mpofu E, ed. Community-Oriented Health Services: Practices Across Disciplines. New York: Springer Publishing Company; 2014.

21. Burris $S$, Ashe $M$, Levin D, Penn M, Larkin M. A transdisciplinary approach to public health law: the emerging practice of legal epidemiology. Annu Rev Public Health. 2016;37:135-148. https://doi. org/10.1146/annurev-publhealth-032315-021841

22. Ramanathan T, Hulkower R, Holbrook J, Penn M. Legal epidemiology: the science of law. J Law Med Ethics J Am Soc Law Med Ethics. 2017;45(1 Suppl):69-72. https://doi.org/10.1177/1073110517703329

23. Burris S, Cloud LK, Penn M. The growing field of legal epidemiology. J Public Health Manag Pract. 2020;26:S4. https://doi.org/10.1097/ PHH.0000000000001133

24. Chriqui JF, O'Connor JC, Chaloupka FJ. What gets measured, gets changed: evaluating law and policy for maximum impact. J Law Med Ethics. 2011;39(1_suppl):21-26. https://doi. org/10.1111/j.1748-720X.2011.00559.x

25. Gutman A, Moran-McCabe K, Ghorashi A, Campbell A, Cloud L. Law as data: using policy surveillance to advance housing studies. Cityscape. 2019;21(1):203-214. https://doi. org/10.2307/26608017

26. Hodge JG. The promise (and pitfalls) of public health policy surveillance. J Health Polit Policy Law. 2016;41(6):1175-1183. https://doi. org/10.1215/03616878-3665976

27. Stone RI, Reinhard SC. The place of assisted living in long-term care and related service systems. Gerontologist. 2007;47(suppl 1):23-32. https://doi.org/10.1093/geront/47.Supplement_1.23

28. Barra M. Nurse delegation of medication pass in assisted living facilities: not all medication assistant technicians are equal. J Nurs Law. 2011;14(1):3-10. https://doi.org/10.1891/1073-7472.14.1.3

29. Carder P, O'Keeffe J, O'Keeffe C. Compendium of Residential Care and Assisted Living Regulations and Policy: 2015 Edition. Office of 
Disability, Aging and Long-Term Care Policy, Office of the Assistant Secretary for Planning and Evaluation, U.S. Department of Health and Human Services; 2015:2017. https://aspe.hhs.gov/basic-repor t/compendium-residential-care-and-assisted-living-regulation s-and-policy-2015-edition

30. Carder PC. State regulatory approaches for dementia care in residential care and assisted living. Gerontologist. 2017;57(4):776-786. https://doi.org/10.1093/geront/gnw197

31. Kaskie BP, Nattinger M, Potter A. Policies to protect persons with dementia in assisted living: déjà vu all over again? Gerontologist. 2015;55(2):199-209. https://doi.org/10.1093/geront/gnu179

32. Barclays Official California Code of Regulations. Chapter 8. Residential Care Facilities for the Elderly (RCFE). 2287000 (2018).

33. New York Codes, Rules and Regulations. Chapter II. Regulations of the Department of Social Services, Subchapter D. Adult-Care Facilities. $18 \S$ 485 (2018).

34. Thomas KS, Dosa D, Gozalo PL, et al. A methodology to identify a cohort of medicare beneficiaries residing in large assisted living facilities using administrative data. Med Care. 2018;56(2):e10-e15. https://doi.org/10.1097/MLR.0000000000000659

35. Zimmerman S, Mitchell CM, Reed D, et al. Outcomes of a dementia care training program for staff in nursing homes and residential care/assisted living settings. Alzheimer's Care Today. 2010;11(2):83-99.

36. Jutkowitz E, Brasure M, Fuchs E, et al. Care-Delivery interventions to manage agitation and aggression in dementia nursing home and assisted living residents: a systematic review and meta-analysis. J Am Geriatr Soc. 2016;64(3):477-488. https://doi.org/10.1111/jgs.13936

37. Kaufer DI, Williams CS, Braaten AJ, Gill K, Zimmerman S, Sloane PD. Cognitive screening for dementia and mild cognitive impairment in assisted living: comparison of 3 tests. J Am Med Dir Assoc. 2008;9(8):586-593. https://doi.org/10.1016/j.jamda.2008.05.006

38. Burris S, Hitchcock L, Ibrahim J, Penn M, Ramanathan T. Policy surveillance: a vital public health practice comes of age. J Health Polit Policy Law. 2016;41(6):1151-1173. https://doi.org/10.1215/03616 878-3665931

39. Burris S. A technical guide for policy surveillance. SSRN Electron J. http://dx.doi.org/10.2139/ssrn.2469895

40. Collins T. Health policy analysis: a simple tool for policy makers. Public Health. 2005;119(3):192-196. https://doi.org/10.1016/j. puhe.2004.03.006

41. Pittman P. Health services research in 2020: data and methods needs for the future. Health Serv Res. 2010;45(5p2):1431-1441. https://doi.org/10.1111/j.1475-6773.2010.01149.x

42. Code of Arkansas Rules and Regulations. 01. Office of Long Term Care - Licensure of Assisted Living Long Term Care Facilities - Level I. 0160601 (2018).

43. Code of Arkansas Rules and Regulations. 02. Office of Long Term Care - Licensure of Assisted Living Long Term Care Facilities - Level II. 0160602 (2018).

44. Code of Arkansas Rules and Regulations. 011. Office of Long Term Care - Licensure of Residential Long Term Care Facilities. 01606011 (2018).

45. Wood J. Using Qualitative Research Strategies for Public Health Law Evaluation: A Methods Monograph for the Public Health Law Research Program. Social Science Research Network. 2012; https://papers. ssrn.com/abstract $=2017750$

46. Presley D, Reinstein T, Webb-Barr D, Burris S. Creating legal data for public health monitoring and evaluation: delphi standards for policy surveillance. J Law Med Ethics. 2015;43(1_suppl):27-31. https://doi.org/10.1111/jlme.12210

47. Bernard HR, Wutich A, Ryan GW. Analyzing Qualitative Data: Systematic Approaches. New York: SAGE Publications; 2016.

48. R Core Team. R: A Language and Environment for Statistical Computing. Vienna: R Foundation for Statistical Computing; 2018. https://www.R-project.org
49. Carcary $M$. The research audit trial-enhancing trustworthiness in qualitative inquiry. Electron J Bus Res Methods. 2009;7(1): 11-24.

50. National Center for Assisted Living. 2018 Assisted Living State Regulatory Review. NCAL; 2018. https://www.ahcancal.org/ncal/ advocacy/regs/Documents/2018_reg_review.pdf

51. Burke G, Orlowski G. A review of dementia training standards across health care settings. Justice in Aging. 2015:7-8. https://www. justiceinaging.org/wp-content/uploads/2015/08/Training-toserve-people-with-dementia-Alz2FINAL.pdf

52. Texas Administrative Code. Chapter 92. Licensing Standards for Assisted Living Facilities. 40 § 92 (2018).

53. Cornell PY, Zhang W, Smith L, Fashaw S, Thomas KS. Developments in the market for assisted living: residential care availability in 2017. J Am Med Directors Assoc. 2020;21(11):1718-1723.

54. Han K, Trinkoff AM, Storr CL, Lerner N, Yang BK. Variation across U.S. Assisted living facilities: admissions, resident care needs, and staffing: U.S. assisted living facilities. J Nurs Scholarsh. 2017;49(1):432. https://doi.org/10.1111/jnu.12262

55. Anderson LM, Brownson RC, Fullilove MT, et al. Evidence-based public health policy and practice: promises and limits. Am J Prev Med. 2005;28(5):226-230. https://doi.org/10.1016/j.amepre.2005.02.014

56. Field RI. Why is health care regulation so complex? Pharm Ther. 2008;33(10):607-608.

57. Field RI. Regulation of Hospitals and Other Health Care Institutions. Health Care Regulation in America: Complexity, Confrontation, and Compromise. Oxford: Oxford University Press; 2007:45.

58. Chriqui JF, Terry-McElrath Y, McBride DC, Eidson SS, VanderWaal CJ. Does state certification or licensure influence outpatient substance abuse treatment program practices? J Behav Health Serv Res. 2007;34(3):309-328. https://doi.org/10.1007/s11414-007-9069-z

59. Blackmon LR, Barfield WD, Stark AR. Hospital neonatal services in the United States: variation in definitions, criteria, and regulatory status, 2008. J Perinatol. 2009;29(12):788-794. https://doi.org/10.1038/ jp.2009.148

60. Kroelinger CD, Okoroh EM, Goodman DA, Lasswell SM, Barfield WD. Designation of neonatal levels of care: a review of state regulatory and monitoring policies. J Perinatol. 2020;40(3):369-376. https://doi.org/10.1038/s41372-019-0500-0

61. Rahman M, Galarraga O, Zinn JS, Grabowski DC, Mor V. The impact of certificate-of-need laws on nursing home and home health care expenditures. Med Care Res Rev. 2016;73(1):85-105. https://doi. org/10.1177/1077558715597161

62. Carder PC, O'Keeffe J. State regulation of medication administration by unlicensed assistive personnel in residential care and adult day services settings. Res Gerontol Nurs. 2016;9(5):209-222. https://doi.org/10.3928/19404921-20160404-03

63. Sonenberg A, Knepper HJ. Considering disparities: how do nurse practitioner regulatory policies, access to care, and health outcomes vary across four states? Nurs Outlook. 2017;65(2):143-153. https://doi.org/10.1016/j.outlook.2016.10.005

\section{SUPPORTING INFORMATION}

Additional supporting information may be found online in the Supporting Information section.

How to cite this article: Smith L, Carder P, Bucy T, et al. Connecting policy to licensed assisted living communities, introducing health services regulatory analysis. Health Serv Res. 2021;00:1-10. https://doi.org/10.1111/1475-6773.13616 